\title{
Clausewitz, Mahan and (Me): The Process of Crafting Naval Strategy
}

\author{
Bruce B. Stubbs
}

\section{Introduction}

I have nothing in common with Clausewitz and Mahan, except for producing naval Service-level strategies based on their ideas for the past thirty years in what is accurately called the "sausage-making" process. What follows are a few of the lessons I have learned about this process-lessons which, for the most part, reoccur because of the constant turnover of civilian and military personnel.

I need to begin with five overarching lessons. First, draft your strategy using the ends-ways-means formula as it provides a clear, easy-to-follow train of logic, and, moreover, ultimately strategy is the interaction between these three variables within the context of risk. As Colin Gray notes: "... the game has always had to be about ends, ways, and means." ${ }^{1}$ Second, accept—do not resist—and address these realities that significantly impact the strategy-making process:

- Whatever their form, all strategies are political documents that reflect accommodations, compromises, overt and hidden agendas, as well as prejudices.

- Senior leaders are caught up in pressing matters of the day and have limited time to reflect on weighty long-term issues. They engage in strategy thinking to solve the pressing matters, like annual budgets, but few have the time or the inclination to engage in long-range, Service-defining strategic thinking.

- Almost everyone, regardless of their staff function, all fancies themselves as a strategist armed with the next big idea for the way ahead. ${ }^{2}$

- The staffing process dulls all strategies. At best, it knocks off the rough edges and protects the interests of the decision makers from dangerous

1 Colin S. Gray, The Future of Strategy (Malden, MA: Polity Press, 2015), 10.

2 Jobie Turner, "Confessions of a Failed Strategist", USAWC War Room (web), 5 November 2019. 
currents. At worse, the tumbling and polishing of the ideas in staff reviews wear them down to almost nothing.

Third, Service-level strategies are strategies signed by a Service Chief describing both the employment of Service forces and the development of Service forces. There is a critically important difference between the employment and development components of a Service-level strategy. For the employment component, the forces are the "means", whereas for the development component, the forces are the "ends". This dichotomy has significant implications when constructing a strategy's framework.

Fourth, do not conflate strategy and planning. Regrettably, much of what passes for strategy is actually planning. Strategy is about setting priorities, such as the allied strategy of "Germany First" in the Second World War. Strategy is your vision of what you want to do, and it provides the parameters for your plan; your plan is how you will actually do it. You don't create a strategy with a plan. You execute it with a plan. ${ }^{3}$ Finally, write your strategy with implementation in mind, as well as the narrative you intend to use to communicate your strategy.

\section{Lesson One: The Five "Ws"}

Before plunging into the strategy production process, spend time answering the five basic "W" questions of journalism-the who, what, where, when and why. Analysing the five "Ws" allows you to identify the problems that create the need for a strategy, the knowledge of which is the starting point for framing the strategy's objectives and determining the best way to craft it. Start the process with an inclusive session to hammer out agreement on the five "Ws". The dividend on this investment will pay out in almost every phase of the process. ${ }^{4}$

\section{Lesson Two: The Strategic Problem}

Focus your strategy on the dominant strategic problem confronting the Service. This forces you to decide on what is important in the current and

3 Huba Wass de Czege, Commentary on "The U.S Army In Multi-domain Operations 2028”, (Carlisle, PA: Strategic Studies Institute/U.S. Army War College Press, April 2020), xix.

4 Jobie Turner. 
future security environment. Without a clear problem to solve, the security environment can become unwieldy and obscure what is important. Moreover, its use keeps you out of the realm of the abstract by forcing concrete, specific terms and coherent solutions into your strategy. ${ }^{5}$ Note, since a Service-level strategy has a force employment component and a force development component, each component requires its own distinct but related problem.

\section{Lesson Three: Central Idea}

Develop a central or "big" idea (such as President John F. Kennedy's "Go to the moon!") that binds the ends, ways and means of your strategy. This big idea must be explicit enough to provide planning guidance to those designated to implement and resource it, but not so detailed as to eliminate creativity and initiative at subordinate levels. ${ }^{6}$ When he was the Under Secretary of the Navy in 2012, Mr Bob Work developed this central idea: "A Fleet built and ready for war ... operated forward to help preserve the peace and protect American, allied, and partner interests." The kernel of his central idea was: "Providing freedom of access in peace and war".

\section{Lesson Four: Theory of Victory}

In addition (or perhaps as an alternative) to beginning with a central idea, identify the theory of victory for your strategy. Good strategies are based on a thorough survey of the resources available and a deep understanding of the adversary and their strategy. This will often result in a sound causal explanation-a theory of victory-that underlies the strategy. As opposed to the central idea, which is a succinct summation of the essence of your strategy, a theory of victory is a detailed description that encapsulates how your ways and means converge with achieving your ends. This ensures coherence in your thinking. A theory of victory explains why you think your actions will work or, in other words, you will succeed for the following

5 Jobie Turner.

6 UK, Royal College of Defence Studies, Getting Strategy Right (Enough) (Shrivenham, UK: Defence Academy of the United Kingdom, 2017), 20. 
reasons. Indeed, a theory of victory may be more appropriately termed a theory of success. ${ }^{7}$

\section{Lesson Five: Purpose}

Know the purpose of your strategy. This lesson is so fundamental, so basic and so obvious that the gentle reader may likely roll his or her eyes in disbelief on reading its inclusion. Unfortunately, more often than not, naval leaders lack clarity on defining and comprehending the purpose of a strategy. Naval Service-level strategies are produced for three overarching purposes: (1) to explain the need for the Service; (2) to explain how the Service meets that need; and (3) to explain where the Service is heading. Any other purpose-such as addressing a changing world, codifying current thinking or sending a signal to potential competitors-is actually a subset of these big three. ${ }^{8}$

\section{Lesson Six: Audience}

Direct your strategy at your intended primary audience. Hard on the heels of understanding your strategy's purpose, this is another rudimentary lesson that is often violated. Most naval Service-level strategies are primarily written for the Office of the Secretary of Defense, Congress, the Joint Staff and the White House Executive Office to ensure that the Service's contribution to national security is understood and resourced. However, senior leaders will invariably direct inclusion of other audiences, such as "deck plate sailors" or the American public, which requires different content and writing style. Service-level strategies help their intended audiences make informed resource and policy decisions. Indeed, they fulfil Samuel Huntington's prescription of explaining the Service's role in implementing national security by describing how, when and where the Service expects to protect the nation. Without such a description, the public and political

7 Huba Wass de Czege.

8 Peter Swartz and Karen Duggan, U.S. Navy Capstone Strategies and Concepts (19811990): Strategy, Policy Concepts and Vision Documents, CQR D0026415.A1/Final December 2011, Arlington, VA: CNA Studies and Analyses, 2011. 
leaders will be confused as to the Service's role, uncertain as to the necessity of its existence and apathetic to its requests for resources. ${ }^{9}$

\section{Lesson Seven: Service Chief Access}

Insist on direct access to your Service Chief to ensure his or her guidance is direct and clear without any interlocutors. It is imperative that you have direct access if your efforts are to yield an effective result which the leadership is committed to executing. Service Chiefs must play an active role because there are too many diverse views and interests to overcome across the Service, which will result in a lowest common denominator product. Frequent and unimpeded access is needed to: (1) implement Service Chief guidance, not guidance altered by staff agendas; (2) provide unfiltered advice to the Service Chief, especially alternative views; and (3) proceed quickly and with a minimum of interference from others.

\section{Lesson Eight: Strategy's Essence}

Make the hard choices, which is the essence of strategy making. Unfortunately, most Service-level strategies, especially at the unclassified level, studiously avoid making hard choices. For an effective strategy, early in your production process: (1) state the challenges confronting the Service and identify essential choices; (2) identify the Service's advantages and adversary weaknesses; (3) establish a pecking order for resources to achieve objectives; (4) state what objectives are not going to be sought; (5) explicitly link the means available for achieving the ends; and (6) make choices and set priorities and policies regarding:

- Capacity vs. capability vs. wholeness

- Near-term vs. long-term risks

- Current readiness vs. recapitalisation

- Diverse, accumulated tasks vs. core missions

- Avoidance of a hollow force

- Operational deployment requirements

9 Samuel P. Huntington, National Policy and the Transoceanic Navy, US Naval Institute, Proceedings vol. 80, No.5, May 1954. 


\section{Lesson Nine: Strategy Consistency}

Incorporate some degree of previous Service Chiefs' strategic thinking into your strategy for consistency. Regardless of the Service Chief, the Service as an institution has enduring strategic objectives and priorities that require incorporation into a consistent strategy for long-term implementation. The benefits are enormous: (1) assured continuity of strategic direction over the fielding of major platforms and weapons systems; (2) no requirement for an incoming Service Chief to craft from scratch a "new" Service strategic direction; (3) unity of effort on the Service's way ahead; (4) reduction of false starts and non-productive efforts; and (5) a consistent Service message for strategic communications. Recognise, however, that the need for an incoming Service Chief to be a champion of "new" concepts, reform or transformation chafes against the requirement of some continuity.

\section{Lesson Ten: Strategy Assessment}

Evaluate your strategy's probable effectiveness against these standards: (1) acceptability, (2) feasibility, (3) suitability to the circumstances, (4) sustainability and (5) adaptability. Without an honest and rigorous evaluation, it is possible to assume a strategy is easier to implement than reality will dictate. Acceptability to the leadership is obvious; if it is not acceptable to your Service Chief, it is going nowhere. Feasibility requires an assessment of whether the Service has the resources to carry out the strategy. A strategy that does not conform to national objectives or circumstances is unsuitable. Sustainability refers to more than supporting resources; it is also whether personnel can carry out its implication over the long term. The apocryphal quote by field marshal von Moltke that "no plan survives contact with the enemy" can be translated as no strategy can survive a changing security environment if it is not adaptable by design.

\section{Lesson Eleven: Maps Not "Eye-Candy"}

Always use maps rather than images of ships, aircraft and personnel in a strategy. The use of such images conveys a lack of seriousness about the strategy document itself. Moreover, the use of such images in "slick and glossy" versions of Service-level strategies often bears little direct relationship to the accompanying text. While the geography represented on a map 
does not define a nation's destiny, it does provide a geospatial context within which a strategy is developed. Indeed, Colin Gray observed that, "Physical geography can be either enabler or disabler, depending on how wisely it is exploited. Geography is a stage set by forces beyond much human control. ... (It) charges a price for the rewards sought through its exploitation." 10 Well-articulated spatial content, with geographic arguments supported by maps, helps strategists to present a more effective case to their audience.

\section{Lesson Twelve: Lists Are Not Strategy}

Do not confuse the compilation of imperatives as your strategy. Though its language is unusually clear, the 2018 National Defense Strategy resembles "The Twelve Days of Christmas" with its litany of twelve objectives, ten investment priorities, eight operational problems and six critical challenges. With so many imperatives to choose from, attempting to prioritise a derivative Service-level strategy based on these broad and sometimes competing priorities can become a minefield. The profusion of priorities allows the process of developing a strategy to devolve into a "buzzword bingo" justification of desired capabilities, which is described as "cherry-picking" desired imperatives. The results are lists of goals, no priorities and ineffective strategy.

\section{Conclusion}

After thirty years in the sausage-making business, there are additional lessons to share, but out of respect for your time (and forbearance), these lessons suffice. My goal is to pass along some useful knowledge about the process, learned the hard way, to those who perform this task now and in the future-a task that President Eisenhower said, "...requires the hardest kind of work from the finest available staff officers". Ike was spot on!

10 Colin S. Gray, Perspectives on Strategy (London: Oxford University Press, 2013), 122. 


\section{Works Cited}

Gray, Colin S., Perspectives on Strategy, London: Oxford University Press, 2013.

Gray, Colin S., The Future of Strategy, Malden, MA: Polity Press, 2015.

Huntington, Samuel P., National Policy and the Transoceanic Navy, Annapolis, MD. US Naval Institute, Proceedings vol. 80, No.5, May 1954.

Royal College of Defence Studies, UK Ministry of Defence, Getting Strategy Right (Enough). Shrivenham, UK: Defence Academy of the United Kingdom, 2017.

Swartz, Peter and Karen Duggan, U.S. Navy Capstone Strategies and Concepts (19811990): Strategy, Policy Concepts and Vision Documents. Arlington, VA: Center for Naval Analyses, CQR D0026415.A1, Final, December 2011.

Turner, Jobie, "Confessions of a Failed Strategist”, War Room, Carlisle, PA: US Army War College: 5 November 2019, https://warroom.armywarcollege.edu/arti cles/failed-strategist-pt1/.

Wass de Czege, Huba, "Commentary on the U.S Army in Multi-domain Operations 2028”, Carlisle, PA: Strategic Studies Institute, U.S. Army War College Press, April 2020. 